\title{
Does hyperlactatemia at admission predict mortality in acute medical patients? A population based cohort study
}

\author{
Felix Haidl ${ }^{1 *}$, Daniel Pilsgaard Henriksen ${ }^{2}$, Mikkel Brabrand ${ }^{3}$, Annmarie Lassen ${ }^{2}$ \\ From Proceedings of the 5th Danish Emergency Medicine Conference \\ Aarhus, Denmark. 18-19 April 2013
}

\section{Background}

An increased lactate level is related to elevated mortality in various subpopulations of critically ill patients, e.g. sepsis and trauma. The aim of the present study was to investigate to which degree lactate is related to increased mortality in a broad cohort of acute medical patients.

\section{Methods}

Single centre cohort study. All adult patients admitted to the medical emergency ward of Odense University Hospital from March 2009 to August 2011, who had an arterial blood gas sample taken within six hours after admission were enrolled. Lactate was stratified in $1 \mathrm{mmol} / \mathrm{l}(\mathrm{mM})$ intervals. Ten-day mortality after admission was assessed through the Danish Centralised Civil Registration system. A further stratification according to systolic hypotension (<90 $\mathrm{mmHg}$ ) was performed. Finally, a survival analysis (Kaplan-Meyer plot) was performed for the first ten days.

\section{Results}

5,318 patients were enrolled, 2,493 male, median age 71 years (5\% and 95\% inter quartiles $25-91$ years). Median lactate level was $1.2 \mathrm{mM}$ ( $5 \%$ and $95 \%$ interquartile range $0.6-3.8 \mathrm{mM}$ ). Ten-day mortality was $382 / 5,318$ (7.2\%). Ten-day mortality increased with increasing lactate at arrival with 79/1,778 (4.2 \%) for lactate 0-0.99 $\mathrm{mM}, 132 / 2,182$ (5.7 \%) for lactate 1.0-1.9 mM, 71/614 (10.3 \%) for lactate 2,0-2,9 mM, 29/174 (14.3\%) for lactate 3.0-3.9 mM, 23/87 (20.9\%) for lactate 4.0-4.9 mM, 6/42 (12.5\%) for lactate 5.0-5.9 mM, 10/18 (35.7 \%) for lactate 6.0-6.9 mM, 7/11 (38.9 \%) for lactate 7.0-7.9 mM and $25 / 30(45.5 \%)$ for lactate $\geq 8 \mathrm{mM}$ (Cuzick's test for trend, $\mathrm{p}<0.001)$. This pattern was more marked in the hypotensive subpopulation. Survival analysis indicated that the increase in mortality was most pronounced within the first five days.

\section{Conclusion}

Lactate levels drawn within six hours of admission is a predictor of mortality among patients admitted to the acute medical ward. Mortality is increased with each $\mathrm{mM}$ of lactate increase.

\section{Authors' details}

${ }^{1}$ Department of Anesthesia, Sygehus Lillebælt, Kolding, Denmark.

${ }^{2}$ Emergency Department, Odense University Hospital, Odense, Denmark.

${ }^{3}$ Department of Medicine, Sydvestjysk Sygehus, Esbjerg, Denmark.

Published: 9 September 2013

doi:10.1186/1757-7241-21-S2-A22

Cite this article as: Haidl et al:: Does hyperlactatemia at admission predict mortality in acute medical patients? A population based cohort study. Scandinavian Journal of Trauma, Resuscitation and Emergency

Medicine 2013 21(Suppl 2):A22.
* Correspondence: felix@haidl.se

'Department of Anesthesia, Sygehus Lillebælt, Kolding, Denmark

Full list of author information is available at the end of the article (c) 2013 Haidl et al; licensee BioMed Central Ltd. This is an Open Access article distributed under the terms of the Creative Commons Attribution License (http://creativecommons.org/licenses/by/2.0), which permits unrestricted use, distribution, and reproduction in any medium, provided the original work is properly cited. 